\title{
Brain and gonadal aromatase activity and steroid hormone levels in female and polymorphic males of the peacock blenny Salaria pavo
}

\author{
David Gonçalves $^{\text {a,* }}$, Magda Teles ${ }^{a}$, João Alpedrinha ${ }^{a}$, Rui F. Oliveira a,b \\ a Unidade de Investigação em Eco-Etologia, CCMAR-CIMAR Laboratório Associado, Instituto Superior de Psicologia Aplicada, Rua Jardim do Tabaco 34, 1049-041 Lisboa, Portugal \\ b Instituto Gulbenkian de Ciência, Rua da Quinta Grande, 6, P-2780-156 Oeiras, Portugal
}

\section{A R T I C L E I N F O}

\section{Article history:}

Received 21 February 2008

Revised 26 July 2008

Accepted 28 July 2008

Available online 9 August 2008

\section{Keywords:}

Aromatase

Sex steroids

Reproductive behavior

Salaria pavo

Peacock blenny

Androgens

Estrogens

Alternative reproductive tactics

\begin{abstract}
A B S T R A C T
In the peacock blenny Salaria pavo large males with well-developed secondary sexual characters establish nests and attract females while small "sneaker" males mimic female sexual displays in order to approach the nests of larger males and parasitically fertilize eggs. These alternative reproductive tactics are sequential, as sneakers irreversibly switch into nesting males. This transition involves major morphologic and behavioral changes and is likely to be mediated by hormones. This study focuses on the role of aromatase, an enzyme that catalyses the conversion of androgens into estrogens, in the regulation of male sexual polymorphism in S. pavo. For this, sex steroid plasma levels and aromatase activity (AA) in gonads, whole brain and brain macroareas were determined in sneakers, transitional males (i.e. sneakers undergoing the transition into nesting males), nesting males and females collected in the field. AA was much higher in ovarian tissue than in testicular tissue and accordingly circulating estradiol levels were highest in females. This supports the view that elevated AA and estradiol levels are associated with the development of a functional ovary. Transitional males are in a non-reproductive phase and had underdeveloped testes when compared with sneakers and nesting males. Testicular AA was approximately 10 times higher in transitional males when compared with sneakers and nesting males, suggesting high AA has a suppressive effect on testicular development. Nesting males had significantly higher plasma levels of both testosterone $(\mathrm{T})$ and 11-ketotestosterone when compared with the other male morphs and previous studies demonstrated that these androgens suppress female-like displays in sneakers. In the brain, AA was highest in macroareas presumably containing hypothalamic nuclei traditionally associated with the regulation of reproductive behaviors. Overall, females presented the highest levels of brain AA. In male morphs AA increased from sneakers, to transitional males, to nesting males in all brain macroareas. These results suggest that the transition into the nesting male tactic is accompanied both by an increase in testicular androgen production and by a higher conversion of androgens into estrogens in the brain. The increase in androgen production is likely to mediate the development of male secondary sexual characters while the increase in brain AA may be related to the behavioral changes associated with tactic transition.
\end{abstract}

(c) 2008 Elsevier Inc. All rights reserved.

\section{Introduction}

Aromatase catalyses the conversion of androgens into estrogens, regulating the local bioavailability of these hormones to target tissues. In vertebrates, it is well established that aromatase plays a key role both in sexual differentiation and in the expression of reproductive behaviors (e.g. Ball and Balthazart, 2004; Baum, 2003; Roselli, 2007; Forlano et al., 2006). In fish, two aromatase isoforms have been described, one preferentially expressed in the ovary (coded by the CYP19a gene) and one preferentially expressed in the brain (coded by the CYP19b gene) (e.g. Chang et al., 1997; Tchoudakova and Callard, 1998). In the gonads, aromatase has been shown to be a key enzyme regulating sexual

\footnotetext{
* Corresponding author. Fax: +351 218860954

E-mail address: davidg@ispa.pt (D. Gonçalves).
}

differentiation in fish. During early development, blocking aromatase will differentiate the gonads into testis (e.g. Komatsu et al., 2006) while estrogen administration will cause the development of ovaries (reviewed in Piferrer, 2001). In adults, aromatase has also been shown to mediate gonadal changes in both protandrous and protogynic species (e.g. Kroon et al., 2005; Lee et al., 2002).

At a brain level, aromatase has been implicated in the process of behavioral sexual differentiation across vertebrates. In general, an increase in aromatase expression or activity in specific regions of the male brain (e.g. hypothalamus-preoptic area) during sensitive developmental phases seems to be critical for the organization of male sexual behaviors (for reviews see Lephart, 1996; Morris et al., 2004). In fish the role of brain aromatase in establishing behavioral sexual differentiation is less clear. In the Nile tilapia and in zebrafish there were no differences in aromatase brain mRNA expression levels between males and females during gonadal differentiation (Kallivre- 
taki et al., 2007; Chang et al., 2005) and in seabass females presented higher levels of brain aromatase mRNA expression during the period of gonadal differentiation but this pattern was reversed shortly after (Blásquez and Piferrer, 2004; see also Piferrer et al., 2005). A role for brain aromatase in regulating sexual behavior in adult fish seems to be more evident. In many species adults show a sexual dimorphism of brain aromatase in regions typically associated with the regulation of sexual behaviors (e.g. Callard et al., 1981; Forlano et al., 2001; Piferrer et al., 2005; Borg, 1987). Moreover, some of these dimorphisms are more evident during the species reproductive season and are regulated by sex steroids (e.g. Forlano and Bass, 2005a). In a study in guppies where aromatase was pharmacologically inhibited, the frequency of male sexual displays decreased (Hallgren et al., 2006), suggesting a parallel with what has been described for birds and mammals, where the local aromatization of testosterone (T) into estradiol $\left(E_{2}\right)$ mediates the expression of some male sexual displays (e.g. Adkins et al., 1980; Vagell and McGinnis, 1997).

Male sexual polymorphism is common among fish. In general, large "bourgeois" males defend reproductive resources such as females or nests while smaller males parasitize the investment of bourgeois males, for example by stealing egg fertilizations (Taborsky, 2008). Often, parasitic males rely on a female-like appearance and behavior in order to access the reproductive resources of bourgeois males and in many species parasitic males irreversibly switch into bourgeois males (reviewed in Oliveira, 2006). This offers an excellent opportunity to study the neuroendocrine regulation of sexual behaviors as both inter and intrasexual variation in reproductive displays occur, and the same individual may switch between femalelike and male displays during its lifetime.

Male sexual polymorphism has been described in a population of the peacock blenny Salaria pavo occurring at the Algarve (Portugal). Here, a scarcity of nest sites promotes a strong male-male competition for nests (Almada et al., 1995; Almada et al., 1994). At the peak of the breeding season nest space becomes a limiting factor and females compete for the access to nesting males. This promotes a reversal of the sex-roles and, unlike other populations where nest sites are not limited, females take the initiative in courtship and display more often courtship displays than males (Almada et al., 1995; J. Saraiva and R. F. Oliveira, unpublished data). The female courtship displays are elaborated and involve flickering the pectoral fins and opening-andclosing the mouth in synchrony while displaying a typical nuptial coloration that can be turned on/off within seconds (Almada et al., 1995). Nesting males may also occasionally court females, usually from the nest, with intense but low-frequency lateral jerking movements (Patzner et al., 1986). In this species sexual dimorphism is marked with males being larger than females and having a pronounced head crest and a pheromone producing anal gland located in the first two rays of the anal fin (Fishelson, 1963; Papaconstantinou, 1979; Patzner et al., 1986). Most small males are female-like in appearance and reproduce by mimicking the female courtship displays in order to approach and access the nests of larger males to parasitically fertilize eggs (Gonçalves et al., 1996). These "sneaker" males are able to deceive nesting males while they are small but the efficiency of female-mimicry decreases with increasing body size (Gonçalves et al., 2005). These male alternative reproductive tactics are sequential and irreversible as after their first breeding season sneakers start to develop secondary sexual characters and may reproduce as nesting males in the following reproductive seasons (T. Fagundes, D. Gonçalves and R. F. Oliveira, unpublished data). During transition the testis regress and a testicular gland develops which is thought to be a main source of gonadal androgens (Oliveira et al., 2001a; Reinboth and Becker, 1986). Because androgens promote the differentiation of male secondary sexual characters and inhibit the sneakers' female-like displays (Gonçalves et al., 2007; Oliveira et al., 2001b), the development of the testicular gland is likely to be a critical step for tactic transition.

In this study the pattern of variation in gonadal and brain aromatase activity (AA) and its relation with circulating steroid levels was characterized in females, sneakers, transitional males and nesting males captured in the field during the breeding season. At a gonadal level variation in aromatase levels may be a mechanism through which sneakers, transitional males and nesting males regulate testicular investment. At a brain level aromatase may contribute to regulate the action of sex steroids on the neural circuits responsible for the expression of female, male and female-like sexual displays.

\section{Methods}

\section{Fish collection}

Fish were collected at Culatra Island (Algarve, southern Portugal) during two consecutive breeding seasons (May-July 2005 and 2006). Females, nesting males, sneaker males and transitional males were collected. The number of animals used in the AA assays and in the hormone analyses are summarized in Table 1 . All nesting males were defending eggs. Females had swollen abdomens, an indicator of ripeness, and after dissection their ovaries were confirmed to have fully developed oocytes. Sneakers were identified as such if they lacked or had poorly developed male secondary sexual characters and sperm could be easily extruded from their vas deferens by gently pressing the abdomen (Gonçalves et al., 1996). Males collected in the field that present these traits will usually court nesting males with female-like displays under laboratory conditions (personal observations). Furthermore, only fish presenting fully developed testes with underdeveloped testicular glands were considered as sneakers (Gonçalves et al., 1996). Transitional males had poorly developed male-like characters, namely the head crest and anal gland. These males have never been observed sneaking or guarding eggs in the field. Because these males are not reproducing, their testes are usually small and this was confirmed during dissection.

Fish were collected during low-tide with a hand-net from bricks used as nests. Animals were immediately lightly anaesthetized with MS222 (Sigma-Aldrich, dilution 1:10,000). Blood was collected from the caudal vein with a heparinized needle and kept in $1.5 \mathrm{ml}$ eppendorf tubes in a mixture of ice and water until being centrifuged, approximately $1-2 \mathrm{~h}$ later. Blood plasma was kept at $-20{ }^{\circ} \mathrm{C}$ until further processing. After blood collection, fish were euthanized by cutting the spinal cord, near the beginning of the dorsal fin. Fish were kept in isolated plastic bags in a mixture of ice and water until dissection, which took place in a field station within $1-2 \mathrm{~h}$. In the field

Table 1

Number of fish from each morphotype used for aromatase activity assays and hormone analyses

\begin{tabular}{|c|c|c|c|c|c|c|c|}
\hline & \multirow{2}{*}{$\begin{array}{l}\text { Total number of } \\
\text { animals collected }\end{array}$} & \multicolumn{3}{|c|}{ Aromatase activity assays } & \multicolumn{3}{|c|}{ Hormone analyses $^{\mathrm{a}}$} \\
\hline & & Whole brain & Brain macroareas & Gonads & $\overline{11-K T}$ & $\mathrm{~T}$ & $\mathrm{E}_{2}$ \\
\hline Nesting males & 42 & 21 & 21 & 22 & $12(0)$ & $12(0)$ & $8(4)$ \\
\hline Transitional males & 10 & 0 & 10 & 9 & $8(2)$ & $6(4)$ & $4(6)$ \\
\hline Sneakers & 30 & 9 & 21 & 20 & $8(1)$ & $6(3)$ & $8(1)$ \\
\hline Females & 37 & 18 & 19 & 23 & $9(1)$ & $8(2)$ & $9(1)$ \\
\hline
\end{tabular}

a The numbers are fish with detectable levels and, within brackets, the number of fish with levels below the detection limit of the assay. 
station, animals were measured and weighed. In males, the development of the head crest was determined by the ratio head height/body height using a caliper. The genital papilla and anal gland area were determined by measuring their major and minor axis under a binocular microscope and assuming an elliptical shape for these structures. Using the same procedure, the area of the testicular gland and of the testes was determined and the relative development of the testicular gland expressed as the average area of both testicular glands/the average area of both testes. The brains and gonads were collected, weighed and immediately kept in liquid nitrogen and later transferred to $\mathrm{a}-80^{\circ} \mathrm{C}$ fridge until further processing. Gonadal weight was used to calculate the gonadosomatic index (gonad weight/ eviscerated weight*100). Aromatase activity was measured from gonadal homogenates for all morphotypes and also from whole brain homogenates of females, nesting males and sneakers using a radiometric assay optimized for blennies. Because transitional males are not as abundant as the other morphs in the population, they were nor included in the whole brain AA assay. In a second sample, brains from females, nesting males, sneakers and also transitional males were split into five macroareas during dissection: telencephalon, optic tectum, cerebellum, diencephalon (excluding the pituitary) and brainstem (Fig. 1) and AA was determined for each macroarea. A comparison of the $A A$ values obtained for sneakers in this study and in a study where sneakers were sacrificed in the lab and immediately dissected (Gonçalves et al. 2007) held similar values (data not shown) suggesting that the field collection method did not induce any significant protein degradation.

During the experimental procedure the "ASAB guidelines for the use of animals in research" were applied.

\section{Hormone analyses}

Free steroid fraction was extracted using previously described methodology (Canário and Scott, 1989; Scott and Canário, 1992). Steroid residues were redissolved in phosphate buffer 0.1 M, pH 7.6, containing gelatine $(1 \mathrm{~g} / \mathrm{L})$, and stored again at $-20^{\circ} \mathrm{C}$ until assayed for $11-\mathrm{KT}, \mathrm{T}$, and $\mathrm{E}_{2}$. The antibody used for the 11-KT assay was kindly donated by $\mathrm{D}$. E. Kime and the corresponding specificity table was published in Kime and Manning (1982). The $\mathrm{E}_{2}$ antibody (reference: 20-ER06) was purchased from Interchim (Montluçon, France) and the cross-reactivity measured by the supplier varied between $1 \%$ for estrone and $0 \%$ for androstenedione. The T antibody (reference: RDITRK2T2) was purchased from Research Diagnostics Inc. (Concord, USA) and the cross-reactivity measured by the supplier varied between $16 \%$ for 5 -alpha-dehydrotestosterone and $<0.01 \%$ for $E_{2}$. For each hormone, circulating plasma levels from all animals were measured within the same assay. Intra-assay coefficients of variation for the $\mathrm{T}, 11-\mathrm{KT}$ and $\mathrm{E}_{2}$ assays were $2.0 \%, 2.3 \%$ and $4.8 \%$, respectively.

\section{Aromatase activity}

In vitro $\mathrm{AA}$ was measured using the tritiated water releasing method adapted from Thompson and Siiteri (1974) and Gonzalez and

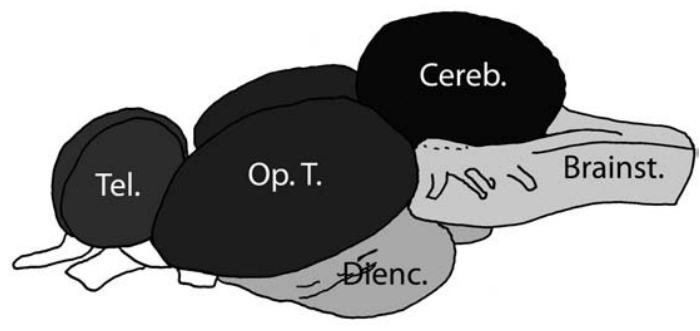

Fig. 1. Division of the brain into five macroareas for aromatase activity determination. Tel.: telencephalon; Op.T.: optic tectum; Dienc.: diencephalon; Cereb.: cerebellum; Brainst.: brainstem.
Piferrer (2002) that uses the conversion of tritiated 3H-androst-4ene-3,17-dione (3H-A) to estrone as an indicator of AA. The optimal values of $\mathrm{pH}$, incubation temperature and substrate concentration for the assay had been previously established in our lab using brain homogenates of two blenny species, S. pavo and Lipophrys pholis. Briefly, the pH of the reaction buffer was tested from 4.5 to 12 at 0.5 intervals and the higher AA was obtained at 7.5 for both species. The incubation temperature was tested from 10 to $60{ }^{\circ} \mathrm{C}$ at $5{ }^{\circ} \mathrm{C}$ intervals and the maximum AA was obtained at $30{ }^{\circ} \mathrm{C}$ for $L$. pholis and at $35^{\circ} \mathrm{C}$ for S. pavo. Finally, the tritiated $3 \mathrm{H}-\mathrm{A}$ concentration was tested from 10 to $300 \mathrm{nM}$ (10 test points) and AA become saturated at approximately $90 \mathrm{nM}$ (data not shown). We thus established a $\mathrm{pH}$ of 7.5, an incubation temperature of $30{ }^{\circ} \mathrm{C}$ and a substrate concentration of $150 \mathrm{nM}$ (to ensure a surplus of substrate) as the conditions for the AA assay in blennies. All other variables (cofactor concentration, volume of sample homogenates, incubation time) were as in the assay developed for seabass by Gonzalez and Piferrer (2002). For whole brain samples, the tissue was first homogenized in a minimum volume of RNase free chilled phosphate buffer solution ( $\mathrm{pH}$ 7.5) with a Teflon homogenizer by applying two $15 \mathrm{~s}$ pulses separated by $30 \mathrm{~s}$ intervals. Half of the volume was transferred to an Eppendorf for other purposes. The other half was further homogenized by applying five $15 \mathrm{~s}$ pulses separated by $30 \mathrm{~s}$ intervals in a tissue:buffer proportion of 1:20. For brain macroareas a fixed volume of $220 \mu \mathrm{l}$ of buffer was used to guarantee two $100 \mu$ aliquots per sample for the AA assay. 3H-A (Perkin-Elmer, Oporto, Portugal) at $150 \mathrm{nM}$ was preincubated for $30 \mathrm{~min}$ at $37{ }^{\circ} \mathrm{C}$ with a NADPH generating system. Aliquots of $100 \mu \mathrm{l}$ of brain homogenates were incubated for $30 \mathrm{~min}$ at $30{ }^{\circ} \mathrm{C}$ with $200 \mu \mathrm{l}$ of the 3H-A/NADPH mix and $100 \mu$ of phosphate buffer in a total volume of $400 \mu \mathrm{l}$. The reaction was terminated by placing the tubes on crushed ice and adding $200 \mu \mathrm{l}$ of $10 \%$ trichloroacetic acid. Samples were then centrifuged for $15 \mathrm{~min}$ for protein precipitation. The supernatant was extracted with three volumes of chloroform and centrifuged for $12 \mathrm{~min} .400 \mu \mathrm{l}$ of dextran coated $(0.5 \%)$ charcoal (5\%) was added to $400 \mu$ of the aqueous phase and centrifuged for $12 \mathrm{~min} .4 \mathrm{ml}$ of scintillation liquid were added to $400 \mu \mathrm{l}$ of the supernatant and tritiated water production quantified in a liquid scintillation counter (Beckman LS6500, 8 min counting). The protein pellet was dissolved with $0.2 \mathrm{~N} \mathrm{NaOH}$ in a $55{ }^{\circ} \mathrm{C}$ water bath with gentle shaking and protein content was quantified using the Lowry method (Lowry et al., 1951). Samples were read at $630 \mathrm{~nm}$ in a spectrophotometer using bovine serum albumin (Sigma-Aldrich, Madrid, Spain) as standard. In all assays, control tubes without substrate or tissue were included and the latest used to calculate and subtract background activity. Tubes with tritiated water (PerkinElmer, Oporto, Portugal) in different concentrations were also included to calculate recovery and this value was used in the final equation to calculate $\mathrm{AA}$ in order to account for losses during the assay. AA was expressed as $\mathrm{pmol} / \mathrm{mg}$ protein/hour.

\section{Statistical procedures}

Differences between morphotypes in morphological variables, hormonal levels, whole brain AA and gonadal AA were tested with one-way ANOVA's. A repeated-measures ANOVA with morphotype as categorical factor and AA in each macroarea as dependent variables was applied to test for differences between morphotypes, macroareas and on the interaction of these two factors. When the ANOVA results were significant, differences between levels were tested with post-hoc Tukey tests. When necessary, data was log or square root transformed to comply with the normality and homocedasticity assumptions of parametric procedures. Differences between morphotypes in $\mathrm{E}_{2} / \mathrm{T}$ and 11-KT/T ratios were tested with the non-parametric Kruskal-Wallis test. When differences were significant the post-hoc Dunn multiple comparison test was applied to assess specific differences between groups. The Spearman's rank correlation coefficient was applied to 


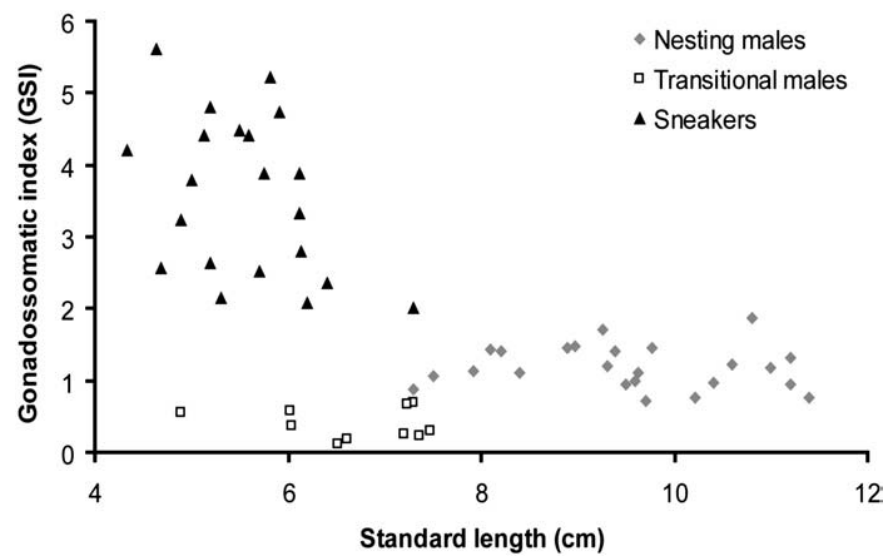

Fig. 2. Gonadosomatic index and standard length of sneaker $(N=21)$, transitional $(N=10)$ and nesting males $(N=24)$.

describe correlations between variables. All tests were two-tailed and the null hypothesis was rejected at a $P$ value below 0.05 .

\section{Results}

Characterization of male morphotypes

The three male morphotypes differed in standard length $\left(F_{2,52}=97.1, P<0.001\right)$ and in their GSI's $\left(F_{2,52}=165.0, P<0.001\right)$. Nesting males were larger than both transitional and sneaker males $(P<0.001)$ and transitional males were larger than sneakers ( $P=0.037$; Fig. 2$)$. Sneakers had the highest GSI $(P<0.001$ in the comparison with transitional and nesting males) and transitional males had the lowest GSI $(P<0.001$ in the comparison with nesting males; Fig. 2).

The head crest, anal gland and genital papilla were more developed in nesting males than in both sneakers and transitional males (Table 2). Transitional males had an intermediate pattern between nesting males and sneakers in these variables but only the anal gland was significantly more developed than in sneakers (Table 2). The testicular gland relative to testes area was higher in transitional males than in the other two male morphs and higher in nesting males than in sneakers (Table 2).

\section{Hormone levels}

The three male morphotypes and females differed in circulating levels of 11-KT $\left(F_{3,33}=6.5, P=0.001\right), \mathrm{T}\left(F_{3,28}=6.2, P=0.002\right)$ and $\mathrm{E}_{2}$ $\left(F_{3,25}=7.9, P<0.001\right)$. Nesting males had higher 11-KT than females $(P=0.007)$, transitional males $(P=0.044)$ and sneakers $(P=0.017$; Fig. $3 \mathrm{~A})$. Females, transitional males and sneakers did not differ in $11 \mathrm{KT}$ levels $(P>0.953$; Fig. 3A). Nesting males also had higher $\mathrm{T}$ levels than females $(P=0.036)$, transitional males $(P=0.034)$ and sneakers $(P=0.044)$. No difference was recorded between the other morphotypes $(P>0.977$; Fig. $3 \mathrm{~B})$. Females had higher $\mathrm{E}_{2}$ levels than nesting

Table 2

Secondary sexual characters in nesting, transitional and sneaker males

\begin{tabular}{llllrl}
\hline & $\begin{array}{l}\text { Nesting } \\
\text { males }\end{array}$ & $\begin{array}{l}\text { Transitional } \\
\text { males }\end{array}$ & Sneakers & $\mathrm{F}_{\text {(d.f. d.f. error) }}$ & $P$ \\
\hline $\begin{array}{l}\text { Head crest index } \\
\text { Anal gland }\end{array}$ & $0.35 \pm 0.02^{\mathrm{a}}$ & $0.14 \pm 0.01^{\mathrm{b}}$ & $0.10 \pm 0.06^{\mathrm{b}}$ & $43.7(2,38)$ & $<0.001$ \\
$\begin{array}{c}\text { development (0-9) } \\
\text { Genital papilla }\end{array}$ & $6.00 \pm 0.28^{\mathrm{a}}$ & $1.90 \pm 0.40^{\mathrm{b}}$ & $0.85 \pm 0.15^{\mathrm{c}}$ & $178.6(2,45)$ & $<0.001$ \\
$\begin{array}{c}\text { development (0-9) } \\
\text { Testicular gland index }\end{array}$ & $0.25 \pm 0.01^{\mathrm{a}}$ & $1.70 \pm 0.47^{\mathrm{b}}$ & $1.14 \pm 0.10^{\mathrm{b}}$ & $120.0(2,52)$ & $<0.001$ \\
& $0.37 \pm 0.04^{\mathrm{b}}$ & $0.06 \pm 0.02^{\mathrm{c}}$ & $49.4(2,48)$ & $<0.001$ \\
\hline
\end{tabular}

Values are expressed as mean \pm S.E. Different letters indicate significant differences $(P<0.05)$. males $(P=0.002)$ and transitional males $(P=0.020)$ and this difference was marginally non-significant for sneakers $(P=0.077)$. No difference occurred between male morphs in circulating $E_{2}$ levels $(P>0.365$; Fig. 3C).

Because both $E_{2}$ and $11 \mathrm{KT}$ can be synthesized from $\mathrm{T}$, the $\mathrm{E}_{2} / \mathrm{T}$ and $11 \mathrm{KT} / \mathrm{T}$ ratios were also compared. For the $\mathrm{E}_{2} / \mathrm{T}$ comparison, transitional males were excluded as only two out of ten individuals had

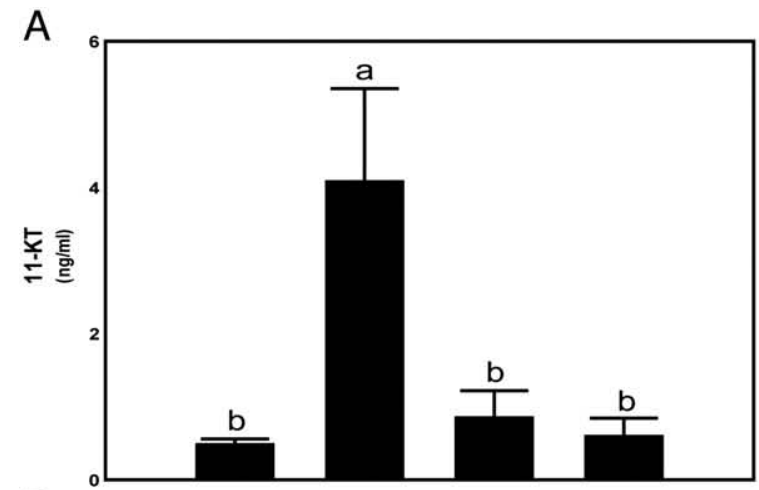

B

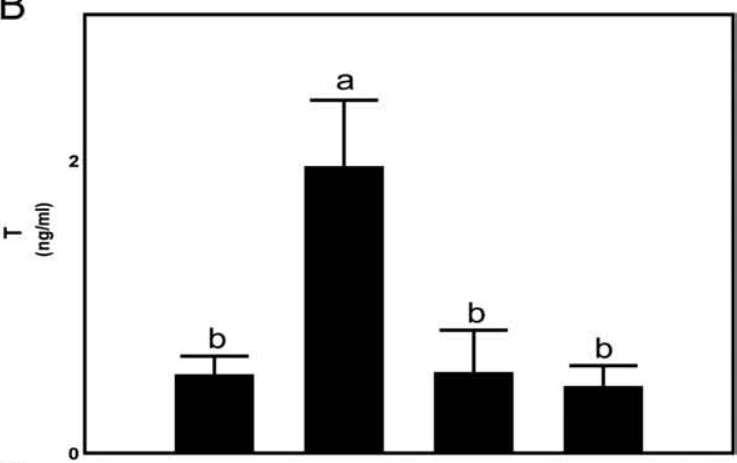

C
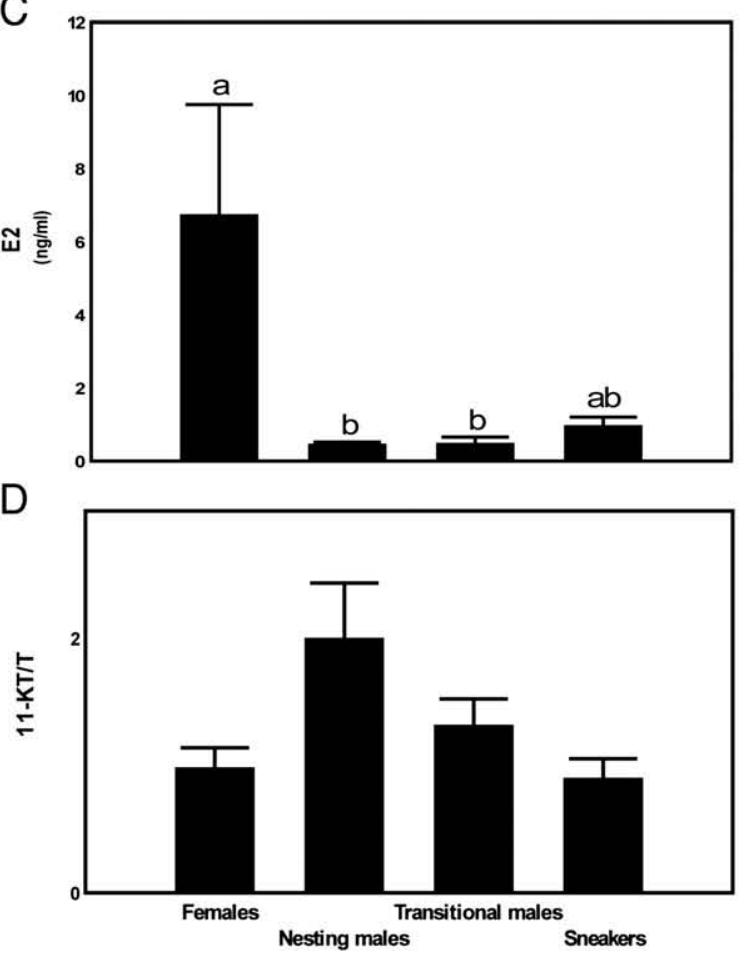

Fig. 3. Circulating levels of (A) 11-KT; (B) $\mathrm{T}$ and; (C) $\mathrm{E}_{2}$; and $11-\mathrm{KT} / \mathrm{T}$ ratios (D). The number of females, nesting males, transitional males and sneakers used in these comparisons were, in this order: $11-\mathrm{KT}(9,12,8,8), \mathrm{T}(8,12,6,6), \mathrm{E}_{2}(9,8,4,8)$ and $11-\mathrm{KT} /$ $\mathrm{T}(7,12,3,3)$. Different letters indicate significant differences $(P<0.05)$. 

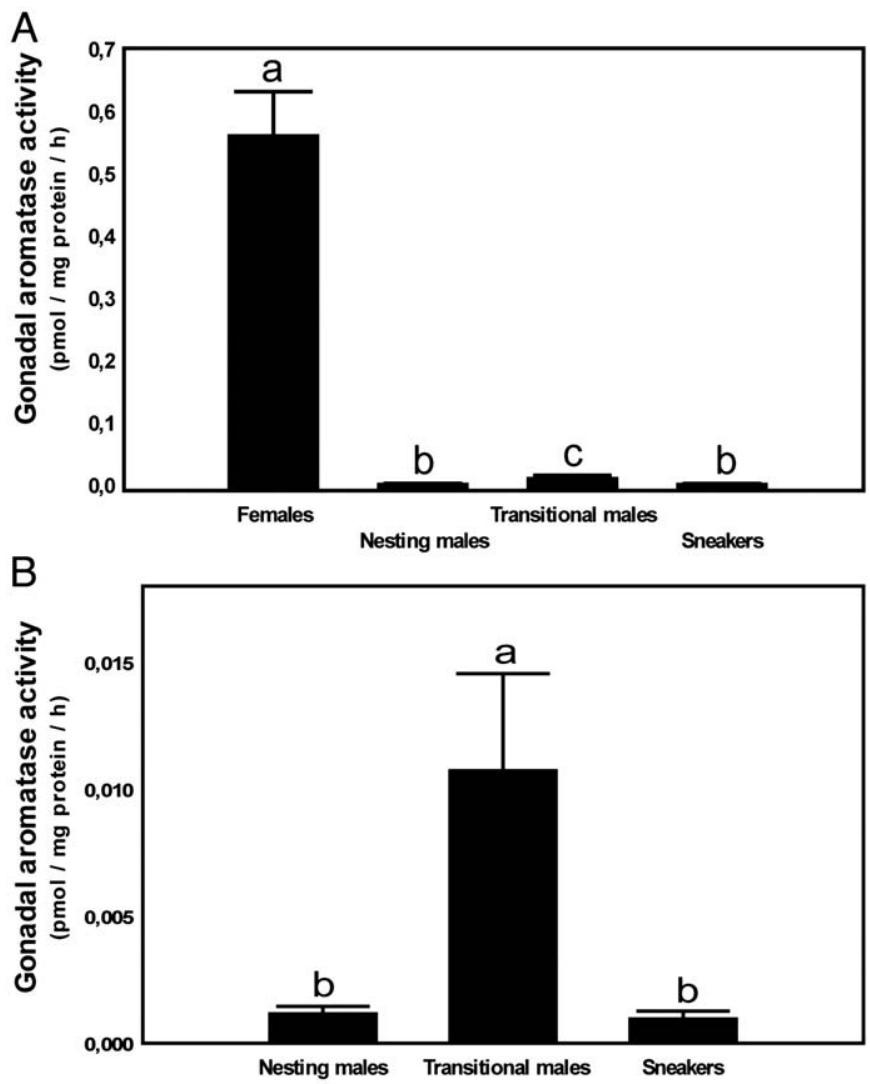

Fig. 4. (A) Aromatase activity measured in ovarian and testicular homogenates of females $(N=23)$, nesting males $(N=22)$, transitional males $(N=9)$ and sneakers $(N=20)$ captured in the field during the reproductive period; (B) the same as in (A) but with only the male morphotypes presented and a different scale in the $Y$ axis. Different letters indicate significant differences $(P<0.05)$.

detectable levels of both $E_{2}$ and $T$. Females, nesting males and sneakers differed in the $\mathrm{E}_{2} / \mathrm{T}$ ratio $(H=14.5$, d.f. $=2, P<0.001)$. Females had significantly higher $\mathrm{E}_{2} / \mathrm{T}$ ratios than nesting males (females: $6.62 \pm 3.09$, $N=7$; nesting males: $0.26 \pm 0.04, N=8 ; P<0.001)$. Sneakers $(0.99 \pm 0.04$, $N=3$ ) had an intermediate pattern but did not differ from females or nesting males $(P>0.05)$.

Nesting males had the highest $11 \mathrm{KT} / \mathrm{T}$ ratio and transitional males had an intermediate pattern between nesting males and sneakers but differences between the four morphotypes were not statistically significant $(H=3.3$, d.f. $=3, P=0.354$; Fig. 3D).

\section{Gonadal aromatase activity}

Gonadal AA differed significantly between females, nesting males, transitional males, and sneakers $\left(F_{3,70}=91.7, P<0.001\right.$; Fig. $\left.4 A\right)$. In the ovaries, AA was at least 50 times higher than in the testes and females had significantly higher AA levels than all male morphs $(P<0.001)$. Transitional males had AA levels approximately 10 times higher than both nesting males $(P=0.029)$ and sneakers $(P=0.020$; Fig. 4B). Nesting males and sneakers males did not differ in testicular AA $(P=0.996)$.

For females, AA in the ovaries did not correlate with circulating levels of $\mathrm{T}\left(r_{\mathrm{s}}=0.24, N=8, P=0.570\right), 11-\mathrm{KT}\left(r_{\mathrm{s}}=0.22, N=9, P=0.575\right)$ or $\mathrm{E}_{2}\left(r_{\mathrm{s}}=-0.19\right.$, $N=9, P=0.397)$. Within males gonadal AA also did not correlate with circulating levels of $\mathrm{T}\left(r_{\mathrm{s}}=-0.22, \mathrm{~N}=23, P=0.307\right), 11-\mathrm{KT}\left(r_{\mathrm{s}}=0.06, N=27\right.$, $P=0.767)$ or $\mathrm{E}_{2}\left(r_{\mathrm{s}}=-0.30, N=19, P=0.209\right)$. AA in the ovaries did not

Fig. 5. Aromatase activity in five brain macroareas from females $(N=19)$, nesting males $(N=21)$, transitional males $(N=10)$ and sneakers $(N=21)$ captured in the field during the reproductive season.
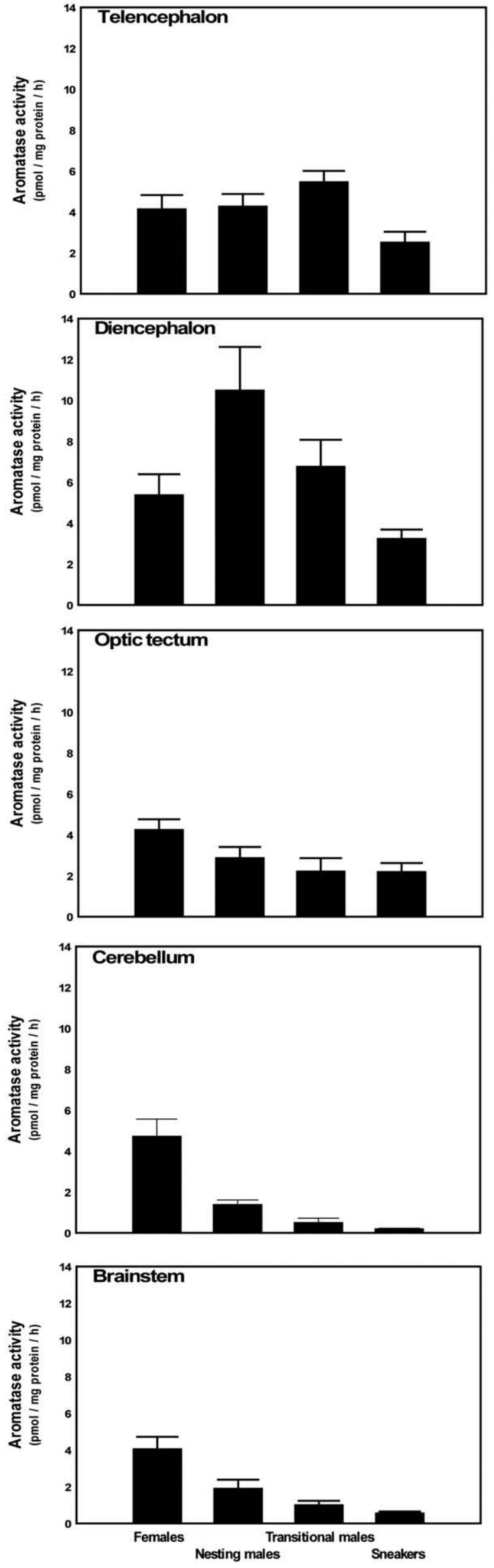
correlate with GSI $\left(r_{\mathrm{s}}=-0.34, N=23, P=0.111\right)$ while in the testes this correlation was negative $\left(r_{\mathrm{s}}=-0.61, N=33, P<0.001\right)$.

\section{Whole brain aromatase activity}

In a first sample, whole brain AA was measured in females, nesting males and sneakers. Whole brain AA differed significantly between morphs $\left(F_{2,30}=7.72, P=0.002\right)$. Females had a significantly higher activity than both nesting males (females: $3.48 \pm 0.25 \mathrm{pmol} / \mathrm{mg}$ protein/h; nesting males: $2.54 \pm 0.25 \mathrm{pmol} / \mathrm{mg}$ protein $/ \mathrm{h} ; P=0.040$ ) and sneakers $(1.95 \pm 0.25 \mathrm{pmol} / \mathrm{mg}$ protein $/ \mathrm{h} ; P=0.003)$. Nesting males had higher AA than sneakers but this difference was not significant $(P=0.376)$.

Overall, brain AA correlated with gonadal AA $\left(r_{\mathrm{s}}=0.55, N=30\right.$, $P=0.001)$. However, this correlation was not significant if only females $\left(r_{\mathrm{s}}=0.43, N=12, P=0.166\right)$ or nesting males and sneakers $\left(r_{\mathrm{s}}=-0.05\right.$, $N=18, P=0.835)$ were included in the analysis. Likewise, brain AA correlated with circulating $E_{2}$ levels if all animals were considered $\left(r_{s}=0.40, N=31, P=0.026\right)$ but not if only females $\left(r_{s}=-0.26, N=12\right.$, $P=0.403)$ or nesting males and sneakers $\left(r_{\mathrm{s}}=0.08, N=19, P=0.736\right)$ were included in the analysis. No correlation between circulating androgen or estrogen levels and brain AA was found, regardless if only females, males or both were included in the analysis $(P>0.156)$.

In nesting males, brain AA did not correlate with any of the morphological variables studied (i.e., standard length, development of the anal gland, genital papilla, head crest and testicular gland and GSI; $P>0.255)$. In sneakers, whole brain AA correlated positively with standard length $\left(r_{S}=0.68, N=9, P=0.041\right)$ and negatively with GSI $\left(r_{s}=-0.67, N=9, P=0.050\right)$. The correlations with the remaining morphological variables were not significant $(P>0.101)$.

\section{Aromatase activity in brain macroareas}

In a second sample, AA in brain macroareas was measured in females, nesting males, sneakers and also in transitional males. A repeated-measures ANOVA showed a significant effect for brain macroarea $\left(F_{4,268}=59.9, \quad P<0.001\right)$, morphotype $\left(F_{3,67}=16.2\right.$, $P<0.001)$, and for the interaction between these two factors $\left(F_{12,268}=8.1, P<0.001\right)$.

The significant interaction between the factor morphotype and macroarea indicates differences between the morphotypes in the pattern of AA across the several macroareas. Females presented the lowest variation in AA levels between different macroareas and no significant differences were detected $(P>0.991$; Fig. 5). The pattern of variation across the five macroareas for the three male morphotypes was similar, with the higher values being recorded in the diencephalon and telencephalon, the lowest in the brainstem and cerebellum and intermediate in the optic tectum (Fig. 5). In nesting males, AA was significantly higher in the diencephalon than in all the other macroareas $(P<0.001)$ and in the telencephalon than in both the cerebellum and brainstem $(P<0.001$; Fig. 5). The remaining comparisons were not significant $(P>0.278)$. In transitional males $A A$ was higher both in the diencephalon and in the telencephalon than in the remaining areas $(P<0.011)$ while no difference occurred between the remaining areas $(P>0.084$; Fig. 5$)$. In sneakers, the diencephalon, telencephalon and optic tectum all had a significantly higher AA than the brainstem and cerebellum $(P<0.005)$ while the remaining comparisons were non-significant $(P>0.622$; Fig. 5$)$.

In the brainstem, optic tectum and cerebellum females had the highest $\mathrm{AA}$. In the cerebellum, the difference towards all male morphs was significant $(P<0.001)$ and in the brainstem females differed from sneakers $(P<0.001$; Fig. 5$)$. All other comparisons between female and male macroareas were not significant $(P>0.080$; Fig. 5$)$.

In the comparison between male morphs, nesting males had significantly higher AA than sneakers in the diencephalon $(P>0.0019)$ and cerebellum $(P=0.021$, Fig. 5). Transitional males had an inter- mediate pattern of AA between nesting males and sneakers in all macroareas except the telencephalon, where AA was higher in transitional males than in the other male morphs (Fig. 5). However, within each macroarea, differences between transitional males and both nesting males and sneakers were not significant $(P>0.156$; Fig. 5).

\section{Discussion}

\section{Gonadal aromatase activity}

By determining the balance between androgens and estrogens in the gonads, aromatase has been shown to play a key role in the process of sexual differentiation and determination in fish. In general, high aromatase and $E_{2}$ levels promote the development of ovaries while low aromatase and $\mathrm{E}_{2}$ levels or high androgen levels promote the development of testes (reviewed in Nagahama, 2000; Piferrer, 2001; Devlin and Nagahama, 2002; Nakamura et al., 2003). For example, treating gonadally undifferentiated fish with estrogens at an appropriate dosage and for an appropriate time length causes the development of ovaries and of a female phenotype, regardless of the sex determination system (reviewed in Piferrer, 2001). Likewise, androgen administration to gonadally undifferentiated fish results in testes development and a male phenotype in many species (e.g. Blásquez et al., 2001; Örn et al., 2003). Masculinization can also be achieved by blocking aromatase at early developmental phases, as it has been demonstrated in both hermaphroditic and gonochoristic species (e.g. Piferrer et al., 1994; Kitano et al., 2000; Afonso et al., 2001; Komatsu et al., 2006). In adults, aromatase also plays a key role during the process of sex change in hermaphroditic species. In protandric species gonadal AA and $\mathrm{E}_{2}$ levels increase during male-to-female sex change (Devlin and Nagahama, 2002). In these species, aromatase inhibitors will block sex reversal (e.g. Lee et al., 2002) and $E_{2}$ administration to males will induce sex change (e.g. Kroon et al., 2005). Inversely, in protogynic species gonadal $A A$ and $E_{2}$ levels decrease during female-to-male sex change (Devlin and Nagahama, 2002) and aromatase inhibitors induce sex reversal (e.g. Kroon and Liley, 2000).

In this study, AA levels in the ovary were more than 50 times higher than in the testes, and in accordance plasma $E_{2}$ levels were higher in females. The results are consistent with the hypothesis that elevated $A A$ and $E_{2}$ levels are associated with the development of a functional ovary. Although AA was generally low in the testes of all male classes when compared to females, transitional males had AA levels approximately 10 times higher than both nesting males and sneakers. These differences probably relate to the fact that, unlike sneakers and nesting males, transitional males are not reproducing. These males are still not large enough to compete with larger males for nests and are no longer female-like in appearance in order to reproduce as sneakers. Accordingly, these males have smaller GSI's when compared with both nesting males and sneakers and have never been observed guarding eggs or sneaking. The negative correlation observed between testicular AA and GSI agrees with high AA in the gonads being responsible for the suppression of testicular development, either by a direct effect of $E_{2}$ or by a decrease in androgen availability. In agreement, AA in the gonads of males with fully developed secondary sexual characters increases outside the breeding season, while the reverse pattern occurs in females (M. Teles, D. Gonçalves, J. Alpedrinha and R. Oliveira, unpublished data), suggesting also an important role for aromatase in the seasonal regulation of gonadal investment. Similar seasonal patterns of variation in gonadal AA in both males and females have been reported for other teleosts (e.g. Li et al., 2007).

In females, the gonads weighed on average $6.5 \%$ of the total body weight (as compared with $1 \%$ of nesting males and $3 \%$ of sneakers) and thus plasma levels of sex steroids were probably highly influenced by 
ovarian AA. The high levels of $E_{2}$ and low levels of androgens in the females' plasma are thus likely to reflect the high AA in the ovaries. In transitional males, testes were only $0.3 \%$ of the total body weight. Thus, although this male class had higher levels of testicular AA than both sneakers and nesting males, circulating $\mathrm{E}_{2}$ levels were not higher in transitional males when compared with the other male classes probably because the overall quantity of $E_{2}$ being produced at the testes and reaching the plasma was small. This does not remove a possible biological significance of the higher AA levels within testicular tissue, where local effects of aromatization can contribute to suppress testes development.

Although differences between the $11-\mathrm{KT} / \mathrm{T}$ ratios were not significant between male morphs, this ratio increased from sneakers to transitional males to nesting males. High 11-KT/T ratios have been associated with the period of maximum spermiation during the seabass seasonal cycle, suggesting that $11-\mathrm{KT}$ may be the main androgen stimulating spermatogenesis and/or spermiogenesis in seabass (Rodriguez et al., 2001). Following this hypothesis, we would expect high 11-KT/T ratios in nesting males and sneakers, as these are reproducing and have enlarged testis, and low ratios in transitional males, as these are not reproducing and have regressed testis. However, in disagreement with this hypothesis, the 11-KT ratio is lowest in sneakers, intermediate in transitional males and highest in nesting males. Alternatively, differences in the 11-KT/T ratio between male morphs may relate with differences in the development of male secondary sexual characters. 11-KT has been suggested to be more important than $\mathrm{T}$ in regulating the development of male-like secondary sexual characters in fish (Oliveira et al., 2005) and in $S$. pavo 11-KT implants to sneakers promotes the development of malelike traits (Oliveira et al., 2001b). Sneakers rely on a female morphology to reproduce and accordingly the $11-\mathrm{KT} / \mathrm{T}$ ratio was lowest in these males. Transitional males are undergoing a morphological change into nesting males and secondary sexual characters are beginning to develop while nesting male probably rely on a full expression of male-like traits to be successful. Accordingly, the 11-KT/ $\mathrm{T}$ ratio was intermediate in transitional males and highest in nesting males.

\section{Brain aromatase activity}

In fish, sex steroids have been shown to modulate behavior by modifying the action of neural circuits. For example, the weakly electric fish of the genus Sternopygus communicates using a sexually dimorphic electrical signal produced by a medullary electric organ. Androgens masculinize the properties of the signal (Few and Zakon, 2001; Mills and Zakon, 1991), probably by modifying the expression of voltage-gated ion channels in the cells of the electric organ (reviewed in Stoddard et al., 2006), while estrogens feminize the properties of this signal (Dunlap et al., 1997). Thus, the action of sex steroids on neural circuits may be partially regulated by local aromatization levels. This has been investigated in the context of male alternative reproductive tactics in the plainfin midshipman Porichthys notatus. In this species nesting males produce vocalizations in order to attract females while females and small female-like sneaker males do not vocalize. In a brain region controlling male courtship vocalizations, AA is higher in females and sneakers than in nesting males and this has been interpreted as a possible mechanism to prevent the masculinization of the vocal system by androgens in non-vocalizing morphs (Schlinger et al., 1999). Additionally, aromatase has also been implicated in the rapid (possibly non-genomic) actions of steroids on neural circuits. For example, in the plainfin midshipman the production of fictive calls induced in vivo by electrical stimulation of a hindbrain vocal pattern generator was rapidly modulated by sex steroids in a sex-specific manner. 11-ketotestosterone promoted these calls in type I nesting males but not in females or type II sneaker males (Remage-Healey and Bass, 2004). Contrarily, T promoted these calls only in females and type II males but this effect seemed to depend on estrogenic effects via the local conversion of $\mathrm{T}$ into $\mathrm{E}_{2}$ by aromatase in females and by direct androgenic effects in type II sneaker males (Remage-Healey and Bass, 2007).

In the studied population of the peacock blenny females display more often courtship behavior than males (Almada et al., 1995) and sneakers reproduce by mimicking female displays (Gonçalves et al., 1996). Androgens (both T and 11-KT) have a suppressive effect on the sneakers' female-like displays while no effect was detected for estrogens (Gonçalves et al., 2007; Oliveira et al., 2001b). Additionally, castrated sneakers exhibit more frequent female-like displays towards males when compared with intact sneakers, suggesting that castration, by decreasing androgen levels, "releases" a suppressive effect caused by gonadal androgens on female-like behavior (Gonçalves et al., 2007). The brain AA pattern partially agrees with these results. In all brain macroareas, sneakers presented the lowest AA of all morphs. Thus, androgens are not being strongly converted into estrogens in the sneakers' brain and circulating androgens presumably can act directly on androgen sensitive brain regions. The question is then why sneakers do not avoid this suppressive effect of androgens on female-like displays? The available data suggests they partially do so. The sneakers testis produces much less androgens than the nesting males testis (Oliveira et al., 2001a). This is probably an adaptation to the female-like tactic in order to diminish the androgen-induced development of male secondary sexual characters and avoid a more significant effect of androgens on the suppression of female-like displays. At the brain level, the pattern of AA increases from sneakers to transitional males to nesting males, in particular in the brain macroarea ought to contain nuclei relevant for the expression of reproductive behaviors (i.e. the diencephalon). This suggests a role for estrogens in the expression of male sexual behaviors in $S$. pavo, as suggested for other vertebrates (e.g. Ball and Balthazart, 2004; Baum, 2003) and fish (e.g. Hallgren et al., 2006). If this is the case, AA in the sneakers brain should balance the androgen-induced behavioral defeminisation with the estrogen-induced behavioral masculinisation. The increase in gonadal androgen production during tactic switching accompanied by the increase in brain AA should allow both a direct effect of androgens on behavioral defeminisation and an indirect effect of androgens through aromatization on behavioral masculinisation. Future experiments should be able to test this hypothesis. It is also likely that the increase in testicular androgen production is not independent from the increase in brain AA during tactic transition. Although AA in the adult brain is thought to be primarily regulated by estrogens in fish (Callard et al., 2001), evidence for an upregulation of brain aromatase by $\mathrm{T}$ in fish also exists (e.g. Forlano and Bass, 2005b), paralleling the known data for mammals (e.g. Roselli, 2007). Thus, the development of the testicular gland and concomitant surge in gonadal androgens may be the key factor inducing both the morphologic and behavioral changes associated with tactic transition.

In this study AA levels were generally higher in the telencephalon and diencephalon, lower in the cerebellum and brain stem and intermediate in the optic tectum. This is in agreement with the results reported for fish and other vertebrates where aromatase levels are consistently high in forebrain regions known to regulate reproductive behaviors, particularly the preoptic nuclei (e.g. Balthazart and Ball, 1998; Forlano et al., 2001; Melo and Ramsdell, 2001). However, the pattern of aromatase activity in the brain was different for females and males. Females presented a lower variation in AA levels between brain macroareas and presented higher levels in posterior regions when compared to males. A similar pattern was described for the medaka, Oryzias latipes, with higher AA levels in anterior regions of the male brain, particularly those containing hypothalamic nuclei, and higher AA levels in posterior areas of the female brain (Melo and Ramsdell, 2001). Interestingly, $E_{2}$ administration to male medaka increased the AA levels in the posterior brain regions (Melo and Ramsdell, 2001). In 
S. pavo, the higher AA in females at posterior brain regions (i.e. cerebellum, brainstem and optic tectum) probably explains why in whole brain homogenates females presented higher AA levels than both nesting males and sneakers. It is possible that the higher $E_{2}$ production in the ovaries is responsible for upregulating aromatase synthesis in the female brain and accordingly brain AA correlated with circulating levels of $E_{2}$.

In summary, AA both at a gonadal and brain level seems to be an important regulatory mechanism underlying the expression of male alternative reproductive tactics. At a gonadal level AA regulates not only sexual differentiation but also the investment in reproduction both ontogenetically and seasonally. At a brain level, variation in AA, in combination with other neuroendocrine mechanisms (e.g. variation in hormone receptors), is a likely mechanism to regulate the action of peripheral hormones on brain circuits underlying the expression of reproductive behaviors.

\section{Acknowledgments}

We are grateful to the direction of the Ria Formosa Nature Park for providing essential logistical support. We are also thankful to Alicia González for her technical assistance with the AA assay and to two anonymous reviewers for their useful comments on a previous version of the manuscript. The study was funded by FCT (UI\&D 331/2001 and PTDC/MAR/71351/2006). D.G. was supported by an FCT post-doc grant (SFRH/BPD/7188/2001).

\section{References}

Adkins, E.K., Boop, J.J., Koutnik, D.L., Morris, J.B., Pniewski, E.E., 1980. Further evidence that androgen aromatization is essential for the activation of copulation in male quail. Physiol. Behav. 24, 441-446.

Afonso, L.O., Wassermann, G.J., Terezinha de Oliveira, R., 2001. Sex reversal in Nile tilapia (Oreochromis niloticus) using a nonsteroidal aromatase inhibitor. J. Exp. Zool. 290, 177-181.

Almada, V.C., Gonçalves, E.J., Santos, A.J., Baptista, C., 1994. Breeding ecology and nest aggregations in a population of Salaria pavo (Pisces, Blenniidae) in an area where nest sites are very scarce. J. Fish Biol. 45, 819-830.

Almada, V.C., Gonçalves, E.J., Oliveira, R.F., Santos, A.J., 1995. Courting femalesecological constraints affect sex-roles in a natural population of the blenniid fish Salaria pavo. Anim. Behav. 49, 1125-1127.

Ball, G.F., Balthazart, J., 2004. Hormonal regulation of brain circuits mediating male sexual behavior in birds. Physiol. Behav. 83, 329-346.

Balthazart, J., Ball, G.F., 1998. New insights into the regulation and function of brain estrogen synthase (aromatase). Trends Neurosci. 21, 243-249.

Baum, M.J., 2003. Activational and organizational effects of estradiol on male behavioral neuroendocrine function. Scand. J. Psychol. 44, 213-220.

Blásquez, M., Piferrer, F., 2004. Cloning, sequence analysis, tissue distribution, and sexspecific expression of the neural form of P450 aromatase in juvenile sea bass (Dicentrarchus labrax). Mol. Cell. Endocrinol. 219, 83-94.

Blásquez, M., Felip, A., Zanuy, S., Carrillo, M., Piferrer, F., 2001. Critical period of androgen-inducible sex differentiation in a teleost fish, the European sea bass. J. Fish Biol. 58, 342-358.

Borg, B., 1987. Stimulation of reproductive behaviour by aromatizable and nonaromatizable androgens in the male three-spined stickleback, Gasterosteus aculeatus L., Proceedings of the V Congress of European Ichthyologists. Stockholm 269-271 1985

Callard, G.V., Petro, Z., Ryan, K.J., Claiborne, J.B., 1981. Estrogen synthesis in vitro and in vivo in the brain of a marine teleost (Myoxocephalus). Gen. Comp. Endocrinol. 43, 243-255.

Callard, G., Tehoudakova, A.V., Kishida, M., Wood, E., 2001. Differential tissue distribution, developmental programming, estrogen regulation and promoter characteristics of Cypl9 genes in teleost fish. J. Steroid Biochem. Mol. Biol. 79, 305-314.

Canário, A.V.M., Scott, A.P., 1989. Synthesis of 20a-hydroxylated steroids by ovaries of the dab (Limanda limanda). Gen. Comp. Endocrinol. 76, 147-158.

Chang, X.T., Kobayashi, T., Kajiura, H., Nakamura, M., Nagahama, Y., 1997. Isolation and characterization of cDNA encoding the tilapia (Oreochromis niloticus) cytochrome P450 aromatase (P450arom): changes in P450arom mRNA, protein and enzyme activity in ovarian follicles during oogenesis. J. Mol. Endocrinol. 18, 57-66.

Chang, X., Kobayashi, T., Senthilkumaran, B., Kobayashi-Kajura, H., Sudhakumari, C.C., Nagahama, Y., 2005. Two types of aromatase with different encoding genes, tissue distribution and developmental expression in Nile tilapia (Oreochromis niloticus). Gen. Comp. Endocrinol. 141, 101-115.

Devlin, R.H., Nagahama, Y., 2002. Sex determination and sex differentiation in fish: an overview of genetic, physiological, and environmental influences. Aquaculture 208, 191-364.
Dunlap, K.D., McAnelly, M.L., Zakon, H.H., 1997. Estrogen modifies an electrocommunication signal by altering the electrocyte sodium current in an electric fish, Sternopygus. J. Neurosc. 17, 2869-2875.

Few, W.P., Zakon, H.H., 2001. Androgens alter electric organ discharge pulse duration despite stability in electric organ discharge frequency. Horm. Behav. 40, 434-442.

Fishelson, L., 1963. Observations on littoral fishes of Israel I. Behaviour of Blennius pavo Risso (Teleostei, Blenniidae). Isr. J. Zool. 12, 67-91.

Forlano, P.M., Bass, A.H., 2005a. Seasonal plasticity of brain aromatase mRNA expression in glia: divergence across sex and vocal phenotypes. J. Neurobiol. 65, 37-49.

Forlano, P.M., Bass, A.H., 2005b. Steroid regulation of brain aromatase expression in glia: female preoptic and vocal motor nuclei. J. Neurobiol. 65, 50-58.

Forlano, P.M., Deitcher, D.L., Myers, D.A., Bass, A.H., 2001. Anatomical distribution and cellular basis for high levels of aromatase activity in the brain of teleost fish: aromatase enzyme and mRNA expression identify glia as source. J. Neurosci. 21, 8943-8955.

Forlano, P.M., Schlinger, B., Bass, A.H., 2006. Brain aromatase: new lessons from nonmammalian model systems. Front. Neuroendocrinol. 27, 247-274.

Gonzalez, A., Piferrer, F., 2002. Characterization of aromatase activity in the sea bass: effects of temperature and different catalytic properties of brain and ovarian homogenates and microsomes. J. Exp. Zool. 293, 500-510.

Gonçalves, D., Matos, R., Fagundes, T., Oliveira, R., 2005. Bourgeois males of the peacock blenny, Salaria pavo, discriminate female mimics from females? Ethology 111, 559-572.

Gonçalves, D., Alpedrinha, J., Teles, M., Oliveira, R.F., 2007. Endocrine control of sexual behavior in sneaker males of the peacock blenny Salaria pavo: effects of castration, aromatase inhibition, testosterone and estradiol. Horm. Behav. 51, 534-541.

Gonçalves, E.J., Almada, V.C., Oliveira, R.F., Santos, A.J., 1996. Female mimicry as a mating tactic in males of the blenniid fish Salaria pavo. J. Mar. Biol. Assoc. U.K. 76, 529-538.

Hallgren, S.L., Linderoth, M., Olsen, K.H., 2006. Inhibition of cytochrome p450 brain aromatase reduces two male specific sexual behaviours in the male Endler guppy (Poecilia reticulata). Gen. Comp. Endocrinol. 147, 323-328.

Kallivretaki, E., Eggen, R.I.L., Neuhauss, S.C.F., Kah, O., Segner, H., 2007. The zebrafish, brain-specific, aromatase cyp19a2 is neither expressed nor distributed in a sexually dimorphic manner during sexual differentiation. Dev. Dyn. 236, 3155-3166.

Kime, D.E., Manning, N.J., 1982. Seasonal patterns of free and conjugated androgens in the brown trout Salmo trutta. Gen. Comp. Endocrinol. 48, 222-231.

Kitano, T., Takamune, K., Nagahama, Y., Abe, S.I., 2000. Aromatase inhibitor and 17alphamethyltestosterone cause sex-reversal from genetical females to phenotypic males and suppression of P450 aromatase gene expression in Japanese flounder (Paralichthys olivaceus). Mol. Reprod. Dev. 56, 1-5.

Komatsu, T., Nakamura, S., Nakamura, M., 2006. Masculinization of female golden rabbitfish Siganus guttatus using an aromatase inhibitor treatment during sex differentiation. Comp. Biochem. Physiol. C. Toxicol. Pharmacol. 143, 402-409.

Kroon, F.J., Liley, N.R., 2000. The role of steroid hormones in protogynous sex change in the Blackeye goby, Coryphopterus nicholsii (Teleostei: Gobiidae). Gen. Comp. Endocrinol. 118, 273-283.

Kroon, F.J., Munday, P.L., Westcott, D.A., Hobbs, J.P., Liley, N.R., 2005. Aromatase pathway mediates sex change in each direction. Proc. R. Soc. Lond. B. Biol. Sci. 272, 1399-1405.

Lee, Y.H., Yueh, W.S., Du, J.L., Sun, L.T., Chang, C.F., 2002. Aromatase inhibitors block natural sex change and induce male function in the protandrous black porgy, Acanthopagrus schlegeli bleeker: possible mechanism of natural sex change. Biol. Reprod. 66, 1749-1754.

Lephart, E.D., 1996. A review of brain aromatase cytochrome P450. Brain Res. Rev. 22 $1-26$.

Li, G.L., Liu, X.C., Lin, H.R., 2007. Seasonal changes of serum sex steroids concentration and aromatase activity of gonad and brain in red-spotted grouper (Epinephelus akaara). Anim. Reprod. Sci. 99, 156-166.

Lowry, O.K., Rosebrough, N.J., Farr, A.L., Randall, R.J., 1951. Protein determination with the Folin phenol reagent. J. Biol. Chem. 193, 265-275.

Melo, A.C., Ramsdell, J.S., 2001. Protein determination with the Folin phenol reagent Environ. Health Perspect. 109, 257-264.

Mills, A., Zakon, H.H., 1991. Coordination of EOD frequency and pulse duration in a weakly electric fish: the influence of androgens. J. Comp. Physiol. [A]. 161, 417-430.

Morris, J.A., Jordan, C.L., Breedlove, S.M., 2004. Sexual differentiation of the vertebrate nervous system. Nat. Neurosci. 7, 1034-1039.

Nagahama, Y., 2000. Gonadal steroid hormones: major regulators of gonadal sex differentiation and gametogenesis in fish. In: Norberg, B., Kjesbu, O., Taranger, G., Andersson, E., Stefansson, S. (Eds.), Proceedings of the Sixth International Symposium on the Reproductive Physiology of Fish. University of Bergen, pp. 211-222.

Nakamura, M., Bhandari, R.K., Higa, M., 2003. The role estrogens play in sex differentiation and sex changes of fish. Fish Physiol. Biochem. 28, 113-117.

Oliveira, R.F., 2006. Neuroendocrine mechanisms of alternative reproductive tactics in fish. In: Sloman, K., Balshine, S., Wilson, R. (Eds.), Behaviour and Physiology of Fish Vol. 24. Elsevier, New York, pp. 297-357.

Oliveira, R.F., Canário, A.V., Grober, M.S., 2001a. Male sexual polymorphism, alternative reproductive tactics, and androgens in combtooth blennies (pisces: blenniidae) Horm. Behav. 40, 266-275

Oliveira, R.F., Carneiro, L.A., Gonçalves, D.M., Canário, A.V., Grober, M.S., 2001b. 11Ketotestosterone inhibits the alternative mating tactic in sneaker males of the peacock blenny, Salaria pavo. Brain. Behav. Evol. 58, 28-37.

Oliveira, R.F., Ros, A.F., Goncalves, D.M., 2005. Intra-sexual variation in male reproduction in teleost fish: a comparative approach. Horm. Behav. 48, 430-439. 
Örn, S., Holbech, H., Madsen, T.H., Norrgren, L., Petersen, G.I., 2003. Gonad development and vitellogenin production in zebrafish (Danio rerio) exposed to ethinylestradiol and methyltestosterone. Aquat. Toxicol. 65, 397-411.

Papaconstantinou, C.A., 1979. Secondary sex characters of blennioid fishes (Pisces: Blenniidae). Thalassographica 3, 57-75.

Patzner, R.A., Seiwald, M., Adlgasser, M., Kaurin, G., 1986. The reproduction of Blennius pavo (Teleostei, Blenniidae) V. Reproductive behavior in natural environment. Zool Anz. 216, 338-350.

Piferrer, F., 2001. Endocrine sex control strategies for the feminization of teleost fish. Aquaculture 197, 229-281.

Piferrer, F., Zanuy, S., Carrillo, M., Solar, I.I., Devlin, R.H., Donaldson, E.M., 1994. Brief treatment with an aromatase inhibitor during sex-differentiation causes chromosomally female salmon to develop as normal, functional males. J. Exp. Zool. 270, 255-262.

Piferrer, F, Blazquez, M., Navarro, L, Gonzalez, A, 2005. Genetic, endocrine, and environmental components of sex determination and differentiation in the European sea bass (Dicentrarchus labrax L.). Gen. Comp. Endocrinol. 142, 102-110.

Reinboth, R., Becker, B., 1986. In vitro-metabolization of $\left[{ }^{14} \mathrm{C}\right]$ testosterone by spermatogenic tissue and the accessory gland of Blennius pavo (Blenniiformes, Teleostei). Gen. Comp. Endocrinol. 5, 11-16.

Remage-Healey, L., Bass, A.H., 2004. Rapid, hierarchical modulation of vocal patterning by steroid hormones. J. Neurosci. 24, 5892-5900.

Remage-Healey, L., Bass, A.H., 2007. Plasticity in brain sexuality is revealed by the rapid actions of steroid hormones. J. Neurosci. 27, 1114-1122.
Rodriguez, L., Begtashi, I., Zanuy, S., Shaw, M., Carrillo, M., 2001. Changes in plasma levels of reproductive hormones during first sexual maturation in European male sea bass (Dicentrarchus labrax L.) under artificial day lengths. Aquaculture. 202, 235-248.

Roselli, C.F., 2007. Brain aromatase: roles in reproduction and neuroprotection. J. Steroid. Biochem. Mol. Biol. 106, 143-150.

Schlinger, B.A., Creco, C., Bass, A.H., 1999. Aromatase activity in the hindbrain vocal control region of a teleost fish: divergence among males with alternative reproductive tactics. Proc. R. Soc. Lond. B. Biol. Sci. 266, 131-136.

Scott, A.P., Canário, A.V.M., 1992. 17a,20b-Dihydroxy-4-pregnen-3-one 20-sulphate: a major new metabolite of the teleost oocyte maturation-inducing steroid. Gen. Comp. Endocrinol. 85, 91-100.

Stoddard, P.K., Zakon, H.H., Markham, M.R., McAnelly, L., 2006. Regulation and modulation of electric waveforms in gymnotiform electric fish. J. Comp. Physiol. [A]. 192, 613-624.

Taborsky, M., 2008. Alternative reproductive tactics in fish. In: Oliveira, R.F., Taborsky, M., Brockmann, H.J. (Eds.), Alternative Reproductive Tactics: An Integrative Approach. Cambridge University Press, Cambridge, pp. 251-299.

Tchoudakova, A., Callard, G.V., 1998. Identification of multiple CYP19 genes encoding different cytochrome P450 aromatase isozymes in brain and ovary. Endocrinology 139, 2179-2189.

Thompson, E.A., Siiteri, P.K., 1974. Utilization of oxygen and reduced nicotinamide adenine-dinucleotide phosphate by human placental microsomes during aromatization of androstenedione. J. Biol. Chem. 249, 5364-5372.

Vagell, M.E., McGinnis, M.Y., 1997. The role of aromatization in the restoration of male rat reproductive behavior. J. Neuroendocrinol. 9, 415-421. 